\title{
Entre meninos e meninas: fronteiras de gênero borradas em contexto de educação infantil ${ }^{1}$
}

\author{
Between boys and girls: gender boundary dissolved in context of \\ early childhood education
}

Ericka Marcelle Barbosa de Oliveira

Lenira Haddad

\begin{abstract}
Resumo: Partindo das relações estabelecidas entre meninas e meninos e dos referenciais teóricos assumidos no estudo, foram estruturadas três categorias principais de análise: "fronteiras borradas entre meninos e meninas", em que o sentido do gênero enquanto fronteira se dilui; "fronteiras marcadas entre meninas e meninos", em que a delimitação e acentuação dessas fronteiras se destacam em momentos específicos; "imagens plurais de masculinidades e feminilidades", em que se evidenciam particularidades, semelhanças e diferenças nas formas como os meninos e as meninas constroem suas masculinidades e feminilidades nas interações estabelecidas com o grupo de pares, mediadas por informações reinterpretadas do mundo adulto. Para efeito deste artigo, as análises centram-se no borramento das fronteiras de gênero entre meninos e meninas e trazem episódios em que comportamentos ou objetos tidos socialmente como tipicamente masculino ou feminino não são assim considerados pelas crianças em suas brincadeiras em um contexto de educação infantil.
\end{abstract}

Palavras-chave: Educação Infantil. Identidade de gênero. Reprodução interpretativa. Cultura de pares. Pesquisa com crianças.

\footnotetext{
${ }^{1}$ Uma versão deste texto foi apresentada durante o III Simpósio Luso-Brasileiro em Estudos da Criança, realizado em julho de 2016 em Braga, Portugal.
}

Latitude, Vol. 10, nํㅡㄹ 2, pp. 425-454, 2016

DOI: https://doi.org/10.28998/2179-5428.20160210 
Entre Meninos e Meninas: Fronteiras de Gênero Borradas em Contexto de Educação Infantil

\begin{abstract}
Starting from the established relationships between girls and boys and the theoretical references assumed in the study, three main categories of analysis were structured: "Boundary dissolved between boys and girls", in which the meaning of gender as a frontier is diluted; "Marked borders between girls and boys", in which the delimitation and accentuation of these borders stand out in specific moments; "Plural images of masculinities and femininities," in which particularities, similarities and differences are evident in the ways boys and girls construct their masculinities and femininities in the interactions established with the peer group mediated by information reinterpreted from the adult world. For the purpose of this article, the analyzes focus on the blurring of gender boundaries between boys and girls and bring episodes in which behaviors or objects socially perceived as typically male or female are not thus considered by children in their play in a context of early childhood education.
\end{abstract}

Keywords: Early Childhood Education. Gender Identity. Interpretative Reproduction. Peer Culture. Research with Children.

\title{
Introdução
}

O presente estudo apresenta os resultados de uma pesquisa com crianças, apoiada em metodologias interpretativas, realizada com treze crianças com idade entre quatro e seis anos, sendo cinco meninos e oito meninas, de uma turma de segundo período de uma instituição de educação infantil da cidade de Maceió/Alagoas.

A pesquisa que fundamenta este artigo buscou investigar como o gênero é significado e representado pelas crianças, quais conhecimentos, saberes e elementos sociais e culturais são atuantes nesse processo de construção do gênero e como as crianças usam o que sabem e aprendem sobre esses elementos nas interações e relações sociais que estabelecem com seus pares e com os adultos e contexto de educação infantil.

O interesse em compreender como o gênero é vivido e significado pelas crianças dentro da cultura de pares se justifica pelo fato de as relações de gênero ainda serem pouco discutidas na educação infantil a partir da 
perspectiva das próprias crianças, fato constatado em um levantamento de pesquisas brasileiras realizado para efeito da investigação que dá origem a este trabalho, considerando o período de 2000 a 2013. Neste levantamento, constatou-se um número crescente de estudos e grupos de pesquisa em torno da temática de gênero e educação infantil, além do aumento de propostas de Grupos de Trabalhos (GT) em eventos científicos ${ }^{2}$ que trazem a articulação da temática gênero e educação infantil, ou gênero e infância,

2 Identifica-se como importante trazer indícios sobre a atenção dispensada à problemática de gênero e educação infantil em eventos científicos recentes, evidenciando que estas são contribuições para o avanço e fortalecimento deste campo específico de pesquisa nos últimos anos. Dentre esses eventos, destacam-se o "Fazendo Gênero 10 - Desafios Atuais dos Feminismos" e o “II Simpósio LusoBrasileiro em Estudos da Criança- Pesquisa com Crianças: desafios éticos e metodológicos". O “Fazendo Gênero 10" foi realizado em Florianópolis, na Universidade Federal de Santa Catarina, em setembro de 2013, contando com dois simpósios temáticos específicos à discussão entre as categorias gênero e infâncias. O Simpósio Temático 010, "As crianças como atores sociais: por que interessam as questões de gênero?", que propôs o diálogo sobre a relação complexa entre abordagens teóricas acerca do gênero e da infância como processos construídos socialmente, e a multiplicidade que essas construções assumem pelas mãos das próprias crianças, nos seus contextos sociais, contando com treze trabalhos inscritos; o Simpósio Temático 103, “Questões de Gênero e Infância nas Produções Midiáticas de, para e com Crianças", com a proposta de reunir trabalhos e pesquisas com foco na forma como a/s infância/s e as diferenças de gênero se evidenciam e tomam forma nas produções midiáticas para crianças (filmes, vídeos, programas de TV, revistas, sites, blogs, videogames, HQs, CDs, etc.), considerando que a experiência da infância na contemporaneidade perpassa pelo imaginário midiático globalizado, que reforçam hierarquias e estereotipias fundadas nas diferenças sexuais. Catorze trabalhos foram inscritos no referido simpósio. Informações disponíveis em http://www.fazendogenero.ufsc.br/10/site/capa. Já o "II Simpósio Luso-Brasileiro em Estudos da Criança", realizado em agosto de 2014, em Porto Alegre, na Faculdade de Educação da Universidade Federal do Rio Grande do Sul, contou com onze eixos temáticos dedicados ao diálogo entre as diferentes áreas de estudos relativas às infâncias a ao estudo das crianças, com destaque para o Eixo Temático 2 - "Infâncias, Gênero e Sexualidade", que apesar de não ter tido divulgado o número exato de trabalhos apresentados, foi possível constatar um número expressivo de estudos inscritos no referido eixo temático. Informações disponíveis em http://www.estudosdacrianca.com.br/site/capa. 
Entre Meninos e Meninas: Fronteiras de Gênero Borradas em Contexto de Educação Infantil

dando uma mostra de como esse campo está se expandindo. Entretanto, permanece uma lacuna já apontada por Felipe (2000, apud FELIPE; GUIZZO, 2008) Rosemberg (2001), Finco (2003), Faria (2006), Buss-Simão (2012), referente a um número limitado de investigações que focalizam o lugar das crianças na construção social das relações de gênero no sistema educacional. Por outro lado, foi possível observar uma tendência crescente de pesquisas com crianças com outras temáticas de investigação, associadas a perspectivas teóricas que tomam como base as dimensões estruturais, sociais e culturais para a investigação de questões que envolvem as crianças e a categoria social infância (ROCHA, 2008).

Nessa perspectiva, destaca-se, mais recentemente, a influência de uma sociologia da infância (PINTO; SARMENTO, 1997; CORSARO, 2002, 2005, 2009a, 2009b, 2011), na qual sociólogos e estudiosos de diferentes nacionalidades vêm refinando e problematizando as abordagens teóricas e tradicionais sobre as categorias infância e criança. Esse movimento crescente de revisão dessas abordagens, influenciado também a partir da crítica feminista sobre a predominância da perspectiva masculina na pesquisa científica, inclui ainda o questionamento de sociólogos sobre o lugar ocupado pelas minorias, tais como os/as negros/as, os/as indígenas, as mulheres e as crianças, nas investigações científicas (CORSARO, 2011).

Ao contrário de outros grupos subordinados, as crianças não têm nenhum representante entre os sociólogos; no entanto, o trabalho de feministas e de acadêmicos sobre minorias sociais, ao menos indiretamente, chamou a atenção para o abandono das crianças (CORSARO, 2011, p. 15).

Para o autor, apesar de as feministas demorarem a perceber a marginalização das crianças no campo da sociologia, suas análises das relações de gênero forneceram uma lente para aquilo que Thorne (1987, apud Corsaro, 2011, p. 15) chamou de "reenquadramento infantil", resultando em importantes estudos recentes sobre as crianças, gênero e identidades. Ou seja, novas formas de conceitualização das crianças na sociologia foram construídas a partir dessa perspectiva e também da ascensão de perspectivas teóricas interpretativistas e construtivistas. Para Corsaro, as suposições sobre a gênese de tudo, das amizades aos 
conhecimentos científicos, são cuidadosamente investigadas como construções sociais, em vez de serem aceitas simplesmente como consequências biológicas ou fatos sociais evidentes.

Isso significa que a infância e todos os objetos sociais (incluindo aspectos como classe, gênero, raça e etnia) são vistos como sendo interpretados, debatidos e definidos nos processos de ação social. Em suma, são vistos como produtos ou construções sociais (CORSARO, 2011, p. 19).

Sob esse viés, quando aplicadas à sociologia da infância, as abordagens construtivistas e interpretativistas argumentam que as crianças são participantes ativas na construção social da infância e na reprodução interpretativa de sua cultura compartilhada, assim como os adultos. É nesse sentido que essas perspectivas se contrastam às teorias tradicionais, que "veem as crianças como consumidoras da cultura estabelecida por adultos" (CORSARO, 2011, p. 19).

Nesta direção, este estudo adota a perspectiva interpretativa da Sociologia da Infância de Corsaro (2002; 2005; 2009a; 2009b; 2011), de que as crianças têm culturas infantis singulares, construídas não de uma simples imitação do mundo adulto, mas sim da produção de significações próprias e da apreensão criativa de informações do mundo adulto de forma a atender aos seus interesses enquanto crianças. Tais considerações revelamse importantes para pesquisar as culturas infantis, compreendendo que as crianças não apenas internalizam a cultura da qual fazem parte, mas contribuem ativamente tanto para a produção como para a mudança cultural. A assunção da perspectiva de Corsaro se dá por este autor considerar que as expectativas de gênero não são simplesmente inculcadas nas crianças pelos adultos, mas sim desafiadas, refinadas e socialmente construídas pelas crianças nas interações com adultos e entre si (CORSARO, 2009).

Assim, considera-se que as crianças ressignificam esses elementos em suas práticas e em seus discursos, também na educação infantil. O contexto educacional torna-se, portanto, um espaço imerso em significações culturais, onde uma amplitude "de conhecimentos socioculturais pode ser produzida, exibida e interpretada (CORSARO, 2011, p. 32). 
Entre Meninos e Meninas: Fronteiras de Gênero Borradas em Contexto de Educação Infantil

Considerando que é no âmbito das relações sociais que os gêneros são construídos, compreende-se que o contexto da educação infantil - dadas as interações que acontecem entre as crianças com seus pares e as diversas relações que estabelecem com os adultos - também atua na construção de identidades de gênero. Com o reconhecimento e reafirmação da educação infantil como espaço e tempo de vivência dos direitos das crianças (BRASIL, 2010), cabe destacar que as crianças passam uma parte significativa de suas rotinas em instituições de educação infantil, trazendo para o interior do contexto escolar uma ampla variedade de saberes advindos de sua participação em variadas rotinas culturais (CORSARO, 2009), contextos e grupos sociais. Nesse sentido, a educação infantil demonstra-se como um espaço interessante e profícuo para os estudos da infância de forma geral, tornando-se importante buscar trazer as crianças como interlocutoras desse processo.

\section{Gênero como categoria de análise das relações sociais}

É possível perceber que desde a infância, nas práticas sociais, meninas e meninos são tratados em dualidade a partir de expectativas construídas socialmente com base nas diferenças entre os sexos masculino e feminino. $\mathrm{O}$ feminino muitas vezes é relacionado à meiguice, delicadeza, ao cuidado e à fragilidade. Ao masculino atribui-se a coragem, a força, o espírito de liderança e a agressividade. Como se um conjunto de características associadas a um gênero estivesse automaticamente excluído do outro.

Entretanto, a forma como meninos e meninas se veem e se identificam se configura de muitos modos diferentes, dependendo das circunstâncias, das associações feitas com diversos grupos, das representações coletivas, dentre outros aspectos (MEYER, 2007; LOURO, 2011). Nesse sentido, Meyer e Soares (2008) destacam que homens e mulheres, meninos e meninas, se constituem mergulhados em diversas instâncias sociais em um processo dinâmico e contínuo, no qual outras questões tais como sexualidade, raça, etnia, religião, classe e geração também estão imbricadas na construção do gênero. A cultura é um campo de luta e contestação onde são produzidos múltiplos, e nem sempre convergentes, sentidos de masculinidade e de feminilidade (MEYER, 2007). Assim, existem muitas e conflitantes formas de definir a feminilidade e a masculinidade, uma vez que nascemos e vivemos em tempos, lugares e 
Ericka Marcelle Barbosa de Oliveira

Lenira Haddad

circunstâncias específicas e distintas.

É neste sentido que o conceito de gênero busca se contrapor à ideia de que existe uma "essência" masculina ou feminina, natural, universal e imutável, enfatizando, em vez disso, os processos de formação histórica, linguística e socialmente determinados (FELIPE; GUIZZO, 2008).

Por gênero, Scott (1998, p. 15 apud GROSSI, 1998, p. 5, tradução da autora) refere-se ao discurso sobre a diferença dos sexos, que "remete não apenas a ideias, mas também a instituições, a estruturas, a práticas cotidianas e a rituais, ou seja, a tudo aquilo que constitui as relações sociais". Para a autora, o discurso é um instrumento de organização do mundo, mesmo se ele não é anterior à organização social da diferença sexual. Nesse sentido, o discurso não reflete a realidade biológica primária, mas constrói o sentido desta realidade. A diferença sexual não é a causa originária a partir da qual a organização social poderia ter derivado; ela é mais uma estrutura social movediça que deve ser ela mesma analisada em seus diferentes contextos históricos.

Scott (1991) propõe que o gênero é um terreno que parece fixado, mas seu sentido é contestado e flutuante. Para a autora (p. 21), a natureza desse processo, dos atores e das ações, só pode ser determinada especificamente se situada no espaço e no tempo. Só podemos escrever a história desse processo se reconhecermos que "homem" e "mulher" são ao mesmo tempo categorias vazias e transbordantes; vazias porque elas não têm nenhum significado definitivo e transcendente; transbordantes porque, mesmo quando parecem fixadas, elas contêm ainda dentro delas definições alternativas negadas ou reprimidas

Entendendo o gênero como uma categoria social e culturalmente construída, a pretensão deste estudo é analisar o gênero como constituinte das identidades de meninos e meninas, em contexto de educação infantil. Nesse sentido, considerando sua perspectiva relacional e não estática, o gênero pode ser visto como algo que os sujeitos sociais "fazem", e não como algo que eles "têm", naturalmente. Como assinala Louro (2011, p. 29, grifo da autora), "a ideia é perceber o gênero fazendo parte do sujeito, constituindo-o". Ou, ainda, o sujeito fazendo o gênero.

Buss-Simão (2012, p. 197), considera que "feminino" e "masculino" são produtos de eventos culturais, "que podem ser denominados como um 'processo de atribuição de gênero', ao invés de ser definido como um conjunto de características, de comportamentos, ou mesmo, de atributos 
Entre Meninos e Meninas: Fronteiras de Gênero Borradas em Contexto de Educação Infantil

físicos". A referida autora argumenta, com base nos estudos de West e Zimmerman (1987), que "fazer gênero" significa criar diferenças entre e dentro de meninas e meninos e entre e dentro de mulheres e homens, diferenças que não são naturais, nem essenciais e nem biológicas. Uma vez que essas diferenças têm sido construídas, elas acabam sendo usadas para reforçar a "essencialidade" do gênero, sendo consideradas e ratificadas como "naturais".

Esse "fazer gênero" é uma ideia relevante para se compreender os processos que participam da construção dos gêneros masculino e feminino. A denominação "Doing gender", ou "fazendo gênero", de acordo com BussSimão (2012), foi utilizada pela primeira vez em um artigo científico pelos autores Candace West e Don H. Zimmerman (1987), causando grande repercussão nos estudos de gênero. A autora destaca a perspectiva sociológica dos autores ao definir o gênero como a realização de uma rotina, metódica e recorrente, e que esse "fazer gênero" é realizado tanto por mulheres como por homens, os quais, como membros da sociedade, passam a ser reféns de sua produção. "Com base nessa prerrogativa, o gênero de uma pessoa não é, simplesmente, um aspecto do que se é, mas, mais especificamente, é algo que se faz, e se faz recorrentemente e em interação com os outros" (BUSS-SIMÃO, 2012, p. 195).

Pereira (2009) também adota essa perspectiva, e esclarece que quando os indivíduos passam a gerir sua conduta com base em normas sobre atividades e atitudes próprias ao seu sexo, e quando passam a descrever, avaliar ou explicar as condutas e traços de outras pessoas em função do sexo delas, eles estão a fazer gênero, estão construindo diferenças entre homens e mulheres que não são naturais e nem biológicas.

Fazer género é, em larga medida, inevitável porque o sexo é (quase) sempre encarado como dimensão estruturante e relevante da interacção. Isto não significa que fazer género implica necessariamente actuar segundo expectativas genderizadas, mas antes que as condutas dos indivíduos são susceptíveis de contínuas avaliações de género (PEREIRA, 2009, p. 116). 
Nesta mesma perspectiva, Butler (2013, p. 200, grifos da autora) desenvolve o conceito de "performatividade de gênero", no qual se compreende que o gênero não é construído como uma identidade estável ou um lócus de ação do qual decorrem vários atos; em vez disso, o gênero é uma identidade tenuamente constituída no tempo, instituído num espaço externo por meio de uma repetição estilizada de atos.

Para a autora, a ação do gênero, o tornar-se feminino e masculino, é uma espécie de ritual social e requer uma "performance repetida", na qual essa repetição é ao mesmo tempo uma reencenação e uma nova experiência de um conjunto de significados já estabelecidos socialmente, além de uma forma mundana e ritualizada de sua legitimação. Butler (2013, p. 200) destaca que embora existam corpos individuais que "encenem" essas significações, que estilizam-se em formas do gênero, essa "ação" é uma ação pública, tem dimensões temporais e coletivas e o seu caráter público envolve também consequências: a "performance", na verdade, é realizada com o objetivo estratégico de manter o gênero em sua estrutura binária; um objetivo que não pode ser atribuído a um sujeito, mas sim, deve ser compreendido como fundador e consolidador do sujeito.

Dessa forma, o efeito do gênero se produz pela "estilização" do corpo, e em consequência, deve ser entendido como a forma corriqueira pela qual os gestos, movimentos e estilos corporais de vários tipos constituem a ilusão de uma identidade permanente marcada pelo gênero. O que há, em verdade, não é um eu permanente de gênero, mas sim um ideal substancial de identidade. Segundo Butler, essa formulação pretende afastar a concepção do gênero do solo de um modelo substancial ${ }^{3}$ da

\footnotetext{
${ }^{3}$ Butler faz críticas a uma metafísica da substância, afirmando que as concepções humanistas do sujeito tendem a presumir uma pessoa substantiva, portadora de atributos essenciais e não essenciais. A autora destaca que não há uma capacidade de moral, razão, deliberação moral ou linguagem que sejam universais. Aponta que como ponto de partida de uma teoria social do gênero, [...] a concepção universal da pessoa é deslocada pelas posições históricas ou antropológicas que compreendem o gênero como uma relação entre sujeitos socialmente constituídos, em contextos específicos. Este ponto de vista relacional ou contextual sugere que o que a pessoa "é" - e a rigor, o que o gênero "é" - refere-se sempre às relações construídas em que ela é determinada. Como fenômeno inconstante e contextual, o gênero não denota como ser substantivo, mas um ponto relativo de convergência
} 
Entre Meninos e Meninas: Fronteiras de Gênero Borradas em Contexto de Educação Infantil

identidade, deslocando-a para um campo que requer concebê-lo como uma "temporalidade social" constituída. Se o gênero é instituído através de uma repetição de atos, "a aparência de substância" é precisamente uma identidade construída, uma realização "performativa" em que os sujeitos passam a acreditar e a exercer sob a forma de uma crença (BUTLER, 2013).

Com base nessas proposições, Louro (2013) aponta que tornar-se um sujeito feminino ou masculino não é algo que aconteça de uma vez por todas, mas algo que implica uma construção que, efetivamente, nunca se completa. Reafirma ainda a ideia de que gênero não é algo que somos, mas algo que fazemos:

Não é algo que se "deduz" de um corpo. Não é natural. Em vez disso, é a própria nomeação de um corpo, sua designação como macho ou como fêmea, como masculino ou feminino, que "faz" esse corpo. O gênero é efeito de discursos. O gênero é performativo (LOURO, 2013, s/p, grifos da autora).

Em outro texto, ao se referir às identidades de gênero e aos modos como os sujeitos vão se construindo como masculinos ou femininos, Louro (2011, p. 106) ressalta que essa construção se dá em suas relações sociais, atravessadas por diferentes discursos, símbolos, representações e práticas, sendo então a representação um dos vários processos sociais que constituem a diferenciação sexual. Por consequência, essa constituição é reiteradamente "'construída, resistida e reconstituída', ela se faz em movimento"' (idem, p. 107).

Contudo, cabe enfatizar, conforme propõe Louro (2011), que a construção do gênero é histórica e incessante e que as relações entre homens e mulheres e os discursos dessas relações estão em constante mudança, o que supõe que as identidades de gênero estão continuamente se transformando, envolvendo um caráter paradoxal de construção mas também de desconstrução dos gêneros.

Dessa forma, assim como atenta Buss-Simão (2012) acompanhar e compreender, a partir da perspectiva das crianças, como esse processo de

entre conjuntos específicos de relações, cultural e historicamente convergentes (BUTLER, 2013, p. 29, grifos da autora). 
"fazer gênero" é vivido e significado por elas, torna-se essencial para os estudos sociais da infância, do mesmo modo que compreender os usos que as crianças dão aos conhecimentos sobre gênero nas relações que estabelecem entre elas e também com os adultos.

\section{Aspectos metodológicos}

O estudo aqui apresentado caracteriza-se como uma pesquisa com crianças, trazendo-as como principais interlocutoras de investigação. A pesquisa, apoiada em metodologias interpretativas (Graue e Walsh, 2003), foi realizada com um grupo de treze crianças com idades entre 4 e 6 anos, sendo cinco meninos e oito meninas, de uma instituição pública de educação infantil da cidade de Maceió, Alagoas.

O destaque dado para a importância da agência das crianças, por meio do que as crianças fazem, do modo como falam, sentem e pensam (Rocha, 2008), justifica-se pelo reconhecimento e assunção das crianças como seres competentes para a ação, para a comunicação e a troca cultural. "Tal legitimação da ação social das crianças resulta também de um reconhecimento e de uma definição contemporânea de seus direitos fundamentais - de provisão, proteção e participação" (ROCHA, 2008, p. 46). Essa perspectiva decorre da problematização de que muitos dos conhecimentos construídos sobre as crianças decorrem de pesquisas realizadas sob a ótica dos adultos, desconsiderando as crianças como sujeitos ativos nos processos de socialização.

Como apontam Delgado e Müller (2008), a investigação com crianças nos coloca inúmeros desafios, principalmente se consideramos as distâncias entre adultos e crianças, e por isso a geração de procedimentos metodológicos deve ser um processo criativo, que possibilite encontrar vários modos de expressão, conhecimentos e interpretações das crianças.

Graue e Walsh (2003, p. 20) destacam que ao se fazer trabalho de campo com crianças, têm-se que buscar "permanentemente maneiras novas e diferentes de ouvir e observar as crianças e de recolher traços físicos de suas vidas". Além disso, os autores estimam o princípio da triangulação, o que significa que "um bom registro de dados contém pontos de vistas recolhidos de tantas perspectivas quanto possível" (GRAUE; WALSH, 2003, p. 127). 
Entre Meninos e Meninas: Fronteiras de Gênero Borradas em Contexto de Educação Infantil

Para dar conta dessa complexidade, na fase de geração de dados foi proposta uma variedade de procedimentos: 1) oficinas de brincadeiras, realizadas no ambiente da brinquedoteca da instituição, especialmente organizado para este fim; 2) oficinas de conversas sobre as brincadeiras realizadas; 3) oficinas de conversas a partir da exibição do filme "O menino do vestido cor de rosa"; 4) oficinas de conversas a partir de imagens de homens, mulheres, meninos e meninas em situações sociais variadas. Todas as sessões das oficinas foram videogravadas e posteriormente transcritas.

A apresentação dos dados foi feita por meio de episódios recortados das videogravações das diversas sessões de oficinas relativas aos quatro procedimentos de geração de dados utilizados. O ponto de partida e de referência para as análises foram as brincadeiras desenvolvidas no espaço da brinquedoteca, conforme a metodologia proposta. Dando relevo às brincadeiras, privilegiou-se episódios que oportunizaram evidenciar e compreender as formas como as crianças, entre pares, experimentavam e atribuíam significados ao gênero durante o brincar, as falas, os gestos, movimentos e ações, que refletem realidades vivenciadas pelos meninos e pelas meninas em rotinas culturais (CORSARO, 2011) mais amplas. Buscouse fazer um contraponto entre os conhecimentos que as crianças manifestaram sobre esse aspecto central nos tempos do brincar e aqueles evidenciados durante as oficinas de conversas com a pesquisadora.

Com base em Thorne (1993) a apresentação dos dados foi organizada em três categorias, estruturadas a partir das análises dos episódios: "fronteiras borradas entre meninos e meninas", em que o sentido do gênero enquanto fronteira se dilui; "fronteiras marcadas entre meninas e meninos", em que a delimitação e acentuação dessas fronteiras se destacam em momentos específicos; "imagens plurais de masculinidades e feminilidades", em que se evidenciam particularidades, semelhanças e diferenças nas formas como os meninos e as meninas constroem suas masculinidades e feminilidades nas interações estabelecidas com o grupo de pares, mediadas por informações reinterpretadas do mundo adulto.

Para efeito deste artigo, as análises centram-se no borramento das fronteiras de gênero entre meninos e meninas e trazem episódios em que comportamentos ou objetos tidos socialmente como tipicamente masculino ou feminino não são assim considerados pelas crianças em suas brincadeiras em um contexto de educação infantil. 
Ericka Marcelle Barbosa de Oliveira

Lenira Haddad

\section{Meninos e meninas nas fronteiras de gênero}

Nas oficinas de brincadeiras, as crianças brincaram entre si indistintamente, não havendo "grupos de meninas" ou "grupos de meninos". As meninas brincaram com e entre os meninos, e os meninos com e entre as meninas. Todavia, durante a fase de geração de dados foi possível perceber algumas situações em que as fronteiras de gênero foram evidenciadas. Em alguns momentos, os meninos foram reprimidos pelas meninas ao usarem a maquiagem e outros objetos socialmente marcados como "femininos". Em outras situações, eles brincaram com a maquiagem e outros artefatos definidos como femininos, e também de cuidar de outras crianças, sem ter suas ações controladas pelas meninas ou pelos meninos.

Thorne (1993) afirma, em seus estudos, que em muitos momentos a separação espacial entre meninos e meninas constitui uma espécie de fronteira de gênero, talvez mais fortemente sentida pelas crianças que querem participar de uma atividade controlada pelo outro sexo. O contato entre os gêneros pode tanto enfraquecer e reduzir um sentido ativo de diferença, bem como, por meio da interatividade com o outro, fortalecer suas fronteiras. Quando as meninas e os meninos estão juntos, de uma forma descontraída e integrada, o sentido de fronteira muitas vezes se dilui. Já em outros momentos, as meninas e os meninos se organizam de modo a enfatizar suas oposições. Como destaca Buss-Simão (2013), é importante não perder de vista que essas separações não são fixas e nem se dão a priori, mas são trabalhadas nas práticas culturais.

As imagens de "fronteira", segundo Thorne (1993, podem erroneamente sugerir uma cerca inflexível que divide as relações sociais em duas partes, o que poderia enfatizar a divisão do masculino e feminino em dois polos opostos. No entanto, a autora promulga que a imagem de "fronteira" deveria ser semelhante a uma espécie de cerca ou muro muito baixos, que podem ser rapidamente desmontados ou borrados. Nesse sentido, decidimos aludir às fronteiras como esses muros baixos, que a às vezes estão bem demarcadas e defendidas, e outras vezes borradas por meninos e meninas, como se, ao estarem juntos em determinados momentos, o sentido de gênero como fronteira se dissolvesse. Ou seja, que o contato "face a face" entre gêneros, por meio da interatividade com o outro, pode enfraquecer um sentido ativo de diferença entre os grupos (THORNE, 1993).

Latitude, Vol. 10, no 2, pp. 425-454, 2016 
Entre Meninos e Meninas: Fronteiras de Gênero Borradas em Contexto de Educação Infantil

No âmbito da pesquisa, as interações entre as crianças nas quais foi possível evidenciar o borramento das fronteiras de gênero se deu principalmente quando meninos e meninas se envolviam juntos em atividades de cuidado com o outro, quando representaram papeis familiares. Também se evidenciaram quando os meninos transgrediram as ordens sociais de uma masculinidade hegemônica e usaram objetos marcados culturalmente como femininos.

Ferreira (2002) aponta que os grupos de pares que constituem o contexto da educação infantil possuem uma identidade partilhada como crianças, ou seja, são membros e participantes num grupo e numa cultura infantil, mas que também possuem identidades particulares e idiossincráticas, que diferenciam e hierarquizam as crianças entre si na sua experiência subjetiva em grupos estruturais diversificados - de gênero, idade e classe social. Muitas vezes as crianças podem se organizar de forma separada por gênero, de acordo com o que entendem ser uma atividade própria para meninos ou para meninas, considerando sua pertença de classe, religião ou etnia. Dessa forma, Ferreira (2002) ressalta que o cuidar muitas vezes associado à uma identidade hegemônica feminina indica uma perspectiva reduzida do gênero enquanto um "papel" feminino, principalmente pela atribuição dessa responsabilidade às mulheres ao longo da história. Todavia, do ponto de vista da ação social, de acordo com as características sociais dos contextos e dos atores sociais envolvidos, "podem subsistir várias masculinidades e feminilidades não-hegemônicas, ainda que reprimidas ou auto-reprimidas por esse consenso e senso comum hegemónico [...], assumindo, então inúmeras valências e nuances" (FERREIRA, 2003, p. 6, grifos da autora).

As brincadeiras de cuidar foram desenvolvidas entre meninos e meninas e só por meninos do grupo pesquisado. A ausência dos estereótipos de gênero nessas brincadeiras de cuidar possivelmente está associada à motivação intrínseca da criança pela brincadeira, evidenciada no uso indiscriminado da área da casa da brinquedoteca. O que se destacou nessas rotinas do brincar foi a expressiva participação dos meninos nas brincadeiras que envolviam o cuidado de outras crianças, como pode ser observado nos episódios a seguir.

Episódio 1: “Meninos Cozinhando” 
Ericka Marcelle Barbosa de Oliveira

Lenira Haddad

Crianças envolvidas no episódio: Olavo ${ }^{4}(5,8)^{5}$, Joel $(5,5)$, Soninha $(5,9)$

Joel mexe em algumas panelas na estante da cozinha. Pega um escorredor e uma panela e coloca em cima do fogão de brinquedo, enquanto canta: "Lalalá, lalalalalá... Tátata, tatatatá...." Ainda cantando, ele volta à estante, pega um sorvete de brinquedo e vai em direção à cama, onde Soninha está deitada. Ela pede a Joel: "tabissêro, tabissêro [travesseiro]". Joel coloca o dedo indicador sobre os lábios e diz, enquanto pensa: "Travesseiro....? Travesseiro...?" Olavo aproxima-se dele e Joel the diz, apontando para Soninha: "Ela quer um travesseiro!" Olavo: "Tavissêro é?" Joel: "Travesseiro!". Olavo pega uma almofada amarela que estava em cima do lençol da cama e entrega-a à Soninha. Depois, pega um violão e sai andando pela sala. Joel dá volta na sala, pulando e cantando: "Lalalalalá... Tatatatá". Olavo pega um isqueiro vazio na estante de brinquedos e diz, indo em direção ao fogão: "Vou ligar o fogo!" Joel corre e aproxima-se de Olavo, dizendo: "Êpa! Esse fogo é meu! Fogo é meu. Tem que acender o fogo aqui" Olavo diz: "Cadê, me dê aqui!" Ele aperta o botão do isqueiro, produzindo faísca. Depois diz: "Dá comida logo", e vai até a estante da cozinha. Olavo diz: "Milho?" Joel pede a Olavo: "Ei bote o fogo de novo! Bote 'os fogo' de novo! Bote o fogo 'ninovo', aí". Olavo coloca um prato em cima da mesa e diz: "Diligou [desligou] foi? Tu?" Joel: "Foi! Não, desliguei não". Olavo "acende" novamente o

\footnotetext{
${ }^{4}$ Foram adotados no estudo nomes fictícios para as crianças, para preservar suas identidades, considerando as especificações do Comitê de Ética em Pesquisa com Seres Humanos sobre a garantia do anonimato dos sujeitos pesquisados. Cabe destacar que a escolha dos nomes fictícios tem relação análoga a seus nomes originais ou apelidos pelos quais as crianças eram chamadas, o que facilitou a identificação das crianças durante todo o processo de geração dos dados.

${ }^{5}$ Idade das crianças.
} 
Entre Meninos e Meninas: Fronteiras de Gênero Borradas em Contexto de Educação Infantil

fogão. Pega o prato em cima da mesa, coloca no fogão e diz: "Dá [Já] tá no fogo, agora é, é..." (não se compreende o que ele fala). Soninha levanta-se da cama e vai em direção aos meninos, dizendo: "Comida, comida, comida". Olavo diz à Soninha: "Nós tá tentando, já, já!" Soninha fala: "Sorvete, sorvete, sorvete, sorvete". Em seguida, ela volta para a cama. Joel vai até a estante de brinquedos. Olavo diz: "Tudo no fogo dá!" Joel volta e diz: "Ei, o fogo se apagou! De novo. De novo!" Olavo senta na cama e chama Soninha: "Filhinha? Comida!" Olavo "acende" o fogo do fogão com o isqueiro. Depois diz: "Cadê o prato? Vou pegar o prato" Soninha aproxima-se de Olavo e diz que quer sorvete com casquinha. Ela pega um sorvete de brinquedo na estante da cozinha e recebe também um sorvete de uma outra menina, que observa a brincadeira. Soninha passa pelo fogão, pega uma panela, coloca na boca e diz: "Gogó!". Joel responde: "Não, isso não é gogó não. Isso é panela!" Ele pega o sorvete da mão de Soninha, faz um gesto com a mão como se colocasse um pó em cima do sorvete, Em seguida, Joel entrega o sorvete de volta a ela, dizendo: "Tome!!" (1 $1^{\text {a }}$ Sessão Oficinas de Brincadeiras - 19/05/2014)

No episódio em destaque, evidencia-se a cooperação entre as crianças na brincadeira de cozinhar entre Joel e Olavo, e de cuidar e ser cuidada entre Olavo e Soninha. O destaque para essa sessão está na ação de cozinhar, que é desempenhada pelos meninos, e na brincadeira de ser o pai da filhinha, realizada por Olavo. A brincadeira dos meninos se dava em torno de acender o fogão e cozinhar e, nesse enredo, Olavo propõe ser o pai de Soninha, quando ele aproxima-se da menina e diz "Filhinha? Comida!", avisando que a comida está pronta, o que enveredou para uma brincadeira em que Olavo cuidava dela. No enredo de brincadeira, parece que Joel não fazia parte da atividade de cuidar de Soninha, pois quando ela aproxima-se do fogão e pega a panelinha dizendo que é "gogó", Joel diz que se trata 
apenas de uma panela. Isso nos leva a inferir que a brincadeira de preparar a comida para a filhinha era apenas entre Olavo e Soninha, e que a brincadeira de acender o fogo e cozinhar era de Joel.

Esse episódio de brincadeiras em que os meninos cozinham evidencia a área da casa como um local de encontro entre os gêneros, onde o cotidiano e o mundo privado podem ser repensados a todo momento (FERREIRA, 2002), pois nesse espaço, as crianças inventam, negociam e recriam, por meio da brincadeira de faz de conta, novos contextos e novos papéis (FINCO, 2010).

Carvalho, Pedrosa e Rosseti-Ferreira (2012, p 170) indicam que, a depender da composição de pares, uma interessante estratégia de interação entre as crianças é o cuidar do outro. As pesquisadoras sugerem que, ao brincar nesse enredo, a criança está, desde cedo, elaborando suas percepções a respeito de relações assimétricas que são características de suas trocas sociais com adultos que cuidam dela. É nas brincadeiras que as crianças desenvolvem seu modo de lidar com essas situações, de acordo com as experiências de relação de que participa.

Ao mesmo tempo, nessas trocas entre pares está se dando não apenas uma transmissão horizontal de modelos e valores culturalmente construídos, mas também a construção de novas formas de percepção e ação que fazem parte da cultura compartilhada naquele grupinho de crianças (CARVALHO; PEDROSA; ROSSETI-FERREIRA, 2012, p. 170).

Destaca-se também o desejo da brincadeira de pai manifestado por Olavo. Em outros momentos da pesquisa de campo, era recorrente as propostas do menino de brincar de pai e filho, ou de mãe e filho. Se alguma das crianças manifestasse interesse nessas "chamadas" feitas por Olavo, dava-se início a esses enredos de brincadeira de cuidar.

Em uma das sessões das oficinas de conversas a partir de imagens, em que Olavo participou com Carlos, ele informa que tem um irmão mais novo. A conversa girou em torno de uma imagem que retratava um homem cozinhando, a qual destacamos a seguir. 
Entre Meninos e Meninas: Fronteiras de Gênero Borradas em Contexto de Educação Infantil

Episódio 2: "Eu cuido do meu irmão quando a minha mãe vai fazer as coisas"

Crianças envolvidas no episódio: Carlos $(5,11)$, Olavo $(5,8)$

Pesquisadora: E na sua casa, Carlos, quem cozinha?

Olavo: É o meu pai e minha mãe que cozinha...

Carlos: Quem cozinha é só a minha mãe. Eu só quero ajudar!

Olavo: Eu ajudo a min... eu só ajudo...

[...]

Carlos: Ela só quer fazer o almoço sozinha ela, é só ela mesmo que faz, meu pai num ajuda...

Olavo: Tu cuida do filho! Até eu cuidei, cuido do meu irmão quando a minha mãe vai fazer as coisas...

$[\ldots]$

Pesquisadora: Olavo, aí quando sua mãe tá fazendo o almoço você cuida do seu irmãozinho, é?

Olavo: É! Tem que cuidar do [...] (fala o nome do irmão)

Pesquisadora: Ah, eu não entendi, fale de novo?

Olavo: $O$ [...] (fala o nome do irmão)! Fica bagunçando... (11 a Sessão- Conversas a partir da exibição de imagens- Grupo 2 - 09/06/14).

No excerto apresentado, Olavo informa que tanto seu pai como sua mãe cozinham em sua casa. O menino diz que "ajuda" a sua mãe cuidando do irmãozinho, para que ele não fique fazendo bagunça enquanto a mãe "faz as coisas", ou seja, o trabalho doméstico.

A partir desses elementos trazidos pelos meninos durante sua conversa com a pesquisadora, pode-se inferir que as experiências que Olavo têm no âmbito familiar, no cuidado com seu irmãozinho e em ver a tarefa de cozinhar ser realizada tanto por seu pai como por sua mãe, ganham dimensão em sua brincadeira de cuidar e cozinhar para sua filhinha de faz de conta, Soninha, e também ao propor a mesma brincadeira diferentes vezes com outras crianças. 
Pode-se argumentar também que as brincadeiras de cuidado em que os meninos se destacaram como cuidadores podem ocorrer em consequência de estarmos diante dessas recentes mudanças na responsabilidade pelas atribuições domésticas entre homens e mulheres, e que vêm fazendo parte cada vez mais da realidade social e cultural das famílias na contemporaneidade. Esses aspectos afetam de alguma forma a infância, são percebidos pelas crianças, em interação com os adultos, e reinterpretados por elas em suas brincadeiras.

Partindo desses conhecimentos, as crianças vão construindo suas identidades pessoais e coletivas por meio de sua interlocução com outros com os quais convivem, principalmente no grupo de pares. Afinal, as crianças são seres sociais e interdependentes, que se organizam como atores sociais nos contatos, nas interações, nas práticas com seus pares (BARBOSA, 2009).

Também foi possível observar que, a partir dessas rotinas de brincadeira de cuidado, outras brincadeiras na mesma temática se desenvolveram, mas com a variação de algumas crianças na composição dos grupos. Destaca-se que Soninha manteve com outros meninos a rotina de brincadeiras de cuidar, tendo as brincadeiras se repetido com outros personagens e com novos enredos, como no episódio a seguir.

Episódio 3: "O jantar já tá prontooo!!"

Crianças envolvidas no episódio: Carlos $(5,11)$, Soninha $(5,9)$, James $(5,8)$

Soninha e Carlos brincam de irmã e irmão na Área da casa. Carlos é o "irmão grande" e Soninha é a "bebê". Soninha está no espaço da cozinha, brincando de preparar alimentos no fogãozinho. James se aproxima dela, senta-se à mesa, e separa com uma faquinha de brinquedo algumas fatias de um bolo rosa de plástico. Carlos faz de conta que a penteadeira é sua loja, que já está voltando para casa e que vai fechar a loja. [...] Ele faz de conta que chega em casa, voltando do trabalho; vai até a cama, e avisa para Soninha, que está na cozinha: “Tá na hora de dormiiir! Vamo, vamo dormir!" Ele coloca as bonecas que estavam em cima da cama no chão. 
Entre Meninos e Meninas: Fronteiras de Gênero Borradas em Contexto de Educação Infantil

Soninha fala para Carlos, enquanto transporta de uma cadeira para o fogão alguns pratinhos com comidinhas de plástico: "Ainda não tá na hora de dormir. Ainda tá cozinhando as coisas. Ainda tá na hora de acordar!". Carlos diz: "Oxe!" Depois ele vai até o fogão, mexe em algumas panelinhas e diz: "Sim, a gente tá fazendo o jantar" [...] Carlos mexe nas panelinhas no fogão, com comidinhas dentro. Ele avisa: "Tá tudo preparado! 'Vamo' comer??? Tá na hora da comidaaa!" Ele leva as panelinhas à mesa e diz: "Tá na hora de comer!" Carlos pega um potinho e faz de conta que polvilha sal na comida, dizendo: "Um pouquinho de sal..." Depois recolhe da mesa algumas fatias de um bolo rosa de brinquedo, com as quais James tinha brincado, e as coloca na estante da cozinha. James está sentado à mesa, tocando um violão. Carlos diz para ele, como se desse uma bronca: "Tá na hora de comer, para com isso!" Depois avisa, em tom de voz alto: "Vamo comer!!! O jantar já ta prontooo!! Tem tudo pra comer!" Enquanto fala, Carlos vai transportando do fogão até a mesa algumas panelinhas e pratinhos com comida. Ele serve a James um pratinho com um peixe de plástico dentro, e diz: "Toma tá? O peixe!". Carlos volta ao fogão, pega outro pratinho com comidas e o coloca na mesa. Em seguida, organiza as comidinhas no centro da mesa, pegando também o pratinho servido a James e fala para ele: "Eu ainda vou pegar o prato! Vou pegar os pratinhos..." [...] Soninha aproxima-se da mesa e diz: "A comida já tá quase pronta!" Carlos diz: "Falta pegar os pratos..." [...] Em seguida, ele e Soninha conversam que vão dormir cada qual em um dos compartimentos da cama. Depois de conversarem sobre dormir, Carlos diz: "Tá na hora de... Tá na hora da gente comer tudo de uma vez!" Ele e Soninha vão em direção à mesa, sentam-se nas cadeiras e junto com James, brincam 
Ericka Marcelle Barbosa de Oliveira

Lenira Haddad

de servir e comer as comidinhas [...] Depois da refeição, as crianças se organizam para dormir na caminha de bonecas e nos compartimentos do lado da caminha, transformados em beliche (2 $2^{\text {a }}$ Sessão Oficinas de Brincadeiras - 20/05/2014).

Esse episódio também evidenciou integração entre os gêneros na brincadeira realizada. A brincadeira foi proposta por Soninha e Carlos aceitou participar. James, que de alguma forma já fazia parte da brincadeira, parece agora caracterizar o enredo como irmão.

A brincadeira das crianças evidenciou outra forma do cuidar, dessa vez em torno de uma relação entre irmã e irmãos, compartilhada entre elas de forma equivalente. Diferente da sessão anterior, que reproduziu uma relação vertical (pai e filha), nessa há uma relação horizontal (entre irmãos), embora exista também verticalidade. A princípio, o cuidar não estava claramente sob responsabilidade de nenhuma das crianças, mas Carlos, em um determinado momento, passou a assumir a atividade de preparar o jantar, inicialmente desenvolvida por Soninha, a irmãzinha. Isso pode ter ocorrido por ele representar o irmão mais velho, o que lhe conferia um certo poder. Ele é dono da loja, e quando volta do trabalho decide que está na hora de dormir; depois, assume a cozinha, decide quando o jantar está pronto, chama várias vezes o irmão para comer, prepara a mesa e serve a comida. Ele evidencia também seu poder de irmão mais velho quando ele dá uma bronca em James, que tocava o violão à mesa, na hora do jantar. $\mathrm{Ou}$ seja, Carlos pode ter ouvido de algum adulto que o momento do jantar não é momento para outras atividades além de alimentar-se.

A partir das observações das sessões de brincadeiras, foi possível identificar que a depender de quem eram os parceiros, meninos ou meninas, as tramas do brincar de faz de conta desenvolviam-se com mais facilidade. Nesse aspecto, Carlos se saiu um bom parceiro para as brincadeiras que as meninas propuseram. Em uma das situações, as meninas comentaram que queriam que a pesquisadora chamasse Carlos para fazer parte do grupo delas de brincadeiras, já que as crianças participavam das sessões de brincadeira sempre em dois grupos:

Pesquisadora: "Eu tenho que chamar o Carlos por que mesmo?" Soninha, que está no espaço da cozinha 
Entre Meninos e Meninas: Fronteiras de Gênero Borradas em Contexto de Educação Infantil

diz: "Por causa que ele é nosso amigo!!!" (6ª Sessão Oficinas de Brincadeiras - 30/05/2014).

Independente do enredo da brincadeira em que se dava maior integração entre os meninos e as meninas, o que se pretende colocar em destaque é a parceria que pode se formar entre os meninos e meninas que brincam juntos, como na percepção evidenciada por Soninha, de que Carlos, por se mostrar acessível em brincar com ela em outras brincadeiras, era seu amigo e das meninas.

Os episódios apresentados mostram que a afirmativa de que os meninos preferem brincar com outros meninos, e as meninas com outras meninas precisa ser revista. Oferecendo espaço e oportunidades para que meninos e meninas brinquem juntos de forma frequente, por meio de brincadeiras de faz de conta, o sentido de fronteira entre os gêneros pode diminuir ou ser ressignificado.

Outro aspecto que se evidenciou nas rotinas de brincadeiras que envolviam o cuidar foi que os meninos também desempenharam entre meninos atividades de cuidado, como pode ser visto no episódio a seguir.

\section{Episódio 4: “Não chora filhinho!"}

Crianças envolvidas no episódio: Joel $(5,5)$, Adson (6)

Joel e Adson estão deitados na parte das prateleiras da cama, Joel na parte de cima e Adson na última prateleira, embaixo, segurando um celular azul. Adson começa a imitar o choro de um bebê. Joel diz: "Não chore não meu filho! Meu filho, não chore! Não chore!" Adson continua a chorar. Ele levanta-se da parte das prateleiras da cama e vai para o outro lado da cama, destinado à caminha de bonecas, onde há um lençol forrado. Do alto, Joel olha Adson e diz para ele: "Tem um monte de ursinho. Você pode pegar qualquer coisa". Adson continua a chorar e deita-se na cama. Joel pergunta: "Cê quer o quê? Quer o quê? Toma essa cama! Durma!" Adson balbucia. Joel diz: "Durma... Durma!!!" Adson "se acalma". Joel deita-se encolhido, recosta a cabeça na almofada 
amarela e fecha os olhos. Um tempo depois, Adson fala ao celular: "Te dadaá!! Dadá?" Joel diz: "Tu é um fio [filho] legal, nunca vi..." Adson chora novamente. Joel continua deitado e diz: "Oi??? Oi fio? Filho??" Adson diz: "Dadá!" Joel diz: "Oi?? Filho!!" Adson pula da cama, falando ao celular: "Da, dadaá, dadaá, papai!!" Ele vai até a estante de brinquedos. Depois volta para cama, deita-se e diz: "Uáaaaaa, uáaaaaaa... Eu era um bebê! Uáaaaaaaa" Joel diz: "Não chore filho!" [...] O bebê Adson continua chorando e Joel canta:

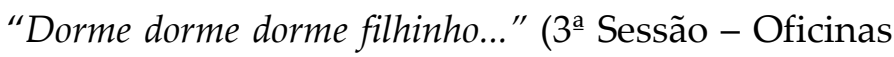
de brincadeiras - 23/05/2014).

No episódio em questão, Joel brinca com Adson, numa situação em que assumem o papel de pai e bebê, caracterizando mais uma relação vertical. A brincadeira envolve um conjunto de representações sobre o ser bebê e o ato de "paternar", evidenciando que essas duas crianças têm conhecimentos a respeito da relação entre o bebê e o pai que cuida. No caso de Adson, ele demonstra saber que o choro do bebê mobiliza a atenção do pai. Joel também evidencia saber o que um pai tem que fazer para acalmar o choro do filho: oferecer "um monte de ursinho", permitindo que ele pudesse "pegar qualquer coisa", oferecer a "caminha de boneca" para o filho dormir, além de dispensar ao filhinho um tratamento carinhoso e atencioso, como na frase "Tué um fio [filho] legal, nunca vi...".

Geralmente as meninas são mais estimuladas que os meninos para o cuidado de bebês. Desde muito novas já recebem bonecas, mamadeiras, chupetas, panelinhas, para "exercitarem" a maternidade e o cuidado desde pequenas. Pouco ou nenhum espaço para a realização da mesma atividade é dado aos meninos.

No entanto, esse episódio mostrou que os meninos são igualmente mobilizados para o cuidado. Essas atividades não são restritas às meninas, e possivelmente as crianças participantes da pesquisa ainda não aprenderam isso, o que demonstra que se a instituição de educação infantil acolhe essas manifestações não estereotipadas e oferece condições, espaços e materiais apropriados, outras formas de posicionamento podem sem engendradas pelas e com as crianças. 
Entre Meninos e Meninas: Fronteiras de Gênero Borradas em Contexto de Educação Infantil

Ao que tudo indica, o contexto da pesquisa oportunizou a expressão desse tipo de brincadeira. Cabe destacar que grande parte das brincadeiras de cuidar ocorreu no beliche, uma estante com três prateleiras que foi organizada como "caminha de bonecas", com bonecas, animais de pelúcia e outros objetos, o que de alguma forma suscitou nas crianças um mote para as brincadeiras de cuidado.

Durante toda a pesquisa de campo, destacou-se a parceria e amizade entre Joel e Adson, que sempre estavam juntos, inclusive nos momentos de atividade na sala da turma e no pátio. Muitas vezes foi possível percebê-los abraçados e chamando um ao outro de "amigo", bem como experimentando juntos as maquiagens durante sessões de brincadeiras na brinquedoteca. Finco (2010) aponta que a amizade ocupa um valor central na cultura de pares e na estruturação da vida cotidiana de meninos e meninas. Os amigos mais próximos são aqueles com os quais as crianças desenvolvem mais atividades em conjunto, experimentam e compartilham um sentido de pertencimento a um determinado grupo. Segundo a autora, a experiência de ter amigos é um meio importante para desenvolver a identidade, ao passo que é com amigos que as crianças, em situação espontânea, mobilizam diferentes competências, como negociação, conflito, transgressões e expressão de sentimentos.

No episódio em destaque, Joel e Adson, ao experimentarem e partilharem dessa atividade de cuidado juntos, não apenas borram as fronteiras de gênero ao reproduzirem interpretativamente uma atividade que é cultural e socialmente marcada como "tipicamente feminina", que é o cuidar de bebês, como têm a possibilidade de expressarem e aprenderem, em interação entre pares, novos valores, novas normas de agir e de se constituírem enquanto meninos, "multiplicando as possibilidades de ser, brincando com possibilidades plurais, com elementos de fantasia e realidade. Assim, experimentam novas brincadeiras, com novos significados e recriam novas formas de ser e de relacionar-se" (FINCO, 2010, p. 129).

Durante a geração de dados, um outro aspecto da interação entre as crianças que evidenciou o borramento das fronteiras de gênero deu-se quando os meninos, sobretudo Joel, desafiaram a imposição de estereótipos e usaram objetos marcados socialmente como femininos, como no episódio a seguir. 
Ericka Marcelle Barbosa de Oliveira

Lenira Haddad

\begin{abstract}
Episódio 5: "Joel experimenta as unhas postiças" Crianças envolvidas no episódio: Joel $(5,5)$

Próximo à cama, Joel observa Bibi e Adson, que brincam ali. Joel segura uma espada de brinquedo e a coloca dentro do short, com o cabo voltado para fora da roupa. Vai até a penteadeira e pega um potinho contendo unhas postiças vermelhas. Ele volta para perto da cama e leva junto o pote com as unhas postiças. Despeja as unhas em cima de uma das prateleiras da cama. Depois, ele vai até a penteadeira e pega a furadeira de brinquedo, que tinha ali deixado. Volta para perto da cama e coloca a furadeira em cima da prateleira. Começa a aplicar as unhas postiças sobre as suas unhas da mão esquerda, analisa o formato, o tamanho, e escolhe as que melhor se encaixam em cada dedo. Parece concentrado e permanece durante três minutos nessa ação. Após encaixar todas as unhas postiças, balança rapidamente a mão. As unhas se soltam e caem em cima da prateleira. Em seguida, ele sai e anda pela sala (2aㅡ Sessão - Oficinas de Brincadeiras 20/05/2014).
\end{abstract}

Considerando que durante a fase de geração de dados as meninas demarcaram fronteiras de gênero quanto ao uso de alguns acessórios "femininos" pelos meninos, pode-se arriscar afirmar que Joel, nesse episódio, mostra-se resistente à essa demarcação ao se permitir experimentar e explorar as unhas postiças. Em uma análise mais detalhada do episódio em destaque, percebe-se que o fato de nenhuma das crianças ter se aproximado de Joel ou o regulado quanto ao uso das unhas postiças vermelhas, possibilitou que ele se prolongasse na experimentação das unhas, que durou cerca de três minutos. Ninguém o interrompe e ele permanece concentrado numa atividade exploratória de medir, analisar o formato das unhas postiças, avaliar qual fica melhor em cada dedo. Após ter encaixado todas as unhas nos dedos da mão esquerda, a exploração chega ao fim e ele simplesmente balança as mãos e as unhas caem de volta na prateleira da caminha, onde ele estava realizando a ação. 
Entre Meninos e Meninas: Fronteiras de Gênero Borradas em Contexto de Educação Infantil

Pôde ser percebido que em momentos livres de brincadeiras, como aconteceu na brinquedoteca, as crianças podem escolher espontaneamente seus brinquedos. Em várias situações, Joel brincou experimentando artefatos materiais considerados "femininos", como uma chapinha rosa de brinquedo e até maquiagem. Entretanto, a escolha do brinquedo pelas crianças muitas vezes está relacionada à forma como ele vem sendo oferecido e permitido pelos adultos que, por meio das cores estereotipadas dos objetos, esperam que eles sejam destinados para um gênero e não para outro. As crianças demonstram, muitas vezes, que não tem construída essa noção de que existem brinquedos ou comportamentos "apropriados" para menino ou para menina, assim como Joel, que brinca livremente com os objetos marcados como "femininos" assim como faz com outros objetos não estereotipados.

\section{Considerações finais}

Assim como assinala Thorne (1993), vários estudos têm a tendência a exagerar a respeito das diferenças e a ignorar as semelhanças entre meninos e meninas que brincam e interagem juntos em variados contextos sociais.

Os episódios analisados evidenciaram que os conhecimentos e usos sobre gênero se destacam e produzem efeitos na forma como as crianças se posicionam enquanto meninos e meninas nas interações estabelecidas entre pares no contexto pesquisado, mediadas por informações reinterpretadas da própria cultura de pares e do mundo adulto.

Durante oficinas de brincadeiras, a área da casa foi usada indiscriminadamente por meninas e meninos, embora tenha se destacado a presença constante dos meninos neste espaço, mais do que das meninas, no quarto e na cozinha da área, brincando entre si e com as meninas de cuidar. Assim, a partir da perspectiva das crianças participantes desta pesquisa, identificou-se nos usos destes espaços de brincadeiras por elas concepções de novos arranjos na divisão das tarefas domésticas entre homens e mulheres.

Diante dessas colocações, o contexto institucional da educação infantil evidencia-se como um espaço imerso em significações culturais, tornando-se um espaço privilegiado para investigar o processo de construção do gênero entre as crianças. A esse respeito, torna-se imperativo 
ressaltar a importância do papel que as instituições de educação infantil têm na promoção e valorização da diversidade entre meninos e meninas, para a promoção de ações que desconstruam visões estereotipadas de gênero, para uma educação e formação não sexista desde a infância e a educação infantil.

O borramento de fronteiras de gênero que se evidenciou nas rotinas de brincadeiras de cuidado do outro entre meninos e meninas, ou de experimentação de artefatos materiais voltados a determinado gênero, permite-nos questionar ainda mais a afirmativa de que há comportamentos e sentimentos tipicamente masculinos e tipicamente femininos. Existem atividades que não são restritas às meninas, ou aos meninos, e possivelmente as crianças que participaram da pesquisa não aprenderam essas imposições do mundo adulto, ou não as aceitam e as confrontam por meio de sua ação social.

Dessa forma, assume-se a compreensão de que muitas diferenças entre homens e mulheres, meninos e meninas não são naturais, mas são construídas cultural e socialmente. Ao trazer as crianças como interlocutoras de investigação, este processo nos possibilita conhecer como elas estão vivendo o gênero masculino e feminino, como é ser menino e ser menina na cultura contemporânea, sob suas perspectivas.

\section{Referências bibliográficas}

BARBOSA, Maria Carmen Silveira. Como a sociologia da infância de William A. Corsaro pode contribuir com as pedagogias das escolas de educação infantil? In: MULLER, Fernanda; CARVALHO, Ana Maria Almeida. (Orgs). Teoria e prática na pesquisa com crianças: diálogos com William Corsaro. São Paulo: Cortez, 2009.

BUSS-SIMÃO, Márcia. Relações sociais de gênero na perspectiva das crianças pequenas na creche. Cadernos de Pesquisa, v.43, n. 148, p. 176197, jan./abr. 2013. Disponível em http://www.scielo.br/pdf/cp/v43n148/09.pdf. Acesso em 14. Dez. 2014. BUSS-SIMÃO, Márcia. Relações sociais em um contexto de educação infantil: um olhar sobre a dimensão corporal na perspectiva de crianças pequenas. 321 p. Tese (Doutorado em Educação). Universidade Federal de 
Entre Meninos e Meninas: Fronteiras de Gênero Borradas em Contexto de Educação Infantil

Santa Catarina, Centro de Ciências da Educação. Programa de PósGraduação em Educação. Florianópolis, SC, 2012.

BUTLER, Judith. Problemas de gênero: feminismo e subversão da identidade. Trad. De Renato Aguiar. 6. ed. Rio de Janeiro: Civilização Brasileira, 2013.

CARVALHO, Ana M. A; PEDROSA, Maria Isabel; ROSSETI-FERREIRA, Maria Clotilde. Aprendendo com a criança de zero a seis anos. São Paulo Cortez, 2012.

CORSARO, Willian A. A reprodução interpretativa no brincar ao "faz de conta" das crianças. Educação, Sociedade \& Culturas. Porto, n. 17, p.113134, 2002.

CORSARO, Willian A. Entrada no campo, aceitação e natureza da participação nos estudos etnográficos com crianças pequenas. Educação e Sociedade. Campinas, vol. 26, n. 91, p. 443-464, Maio/Ago, 2005. Disponível em: <http://www.cedes.unicamp.br > Acesso em 12. Jan. 2014.

CORSARO, Willian A. Reprodução interpretativa e cultura de pares. In: MULLER, Fernanda; CARVALHO, Ana Maria Almeida. (Orgs). Teoria e prática na pesquisa com crianças: diálogos com William Corsaro. São Paulo: Cortez, 2009a.

CORSARO, Willian A. Métodos etnográficos no estudo da cultura de pares e das transições iniciais na vida das crianças. In: MULLER, Fernanda; CARVALHO, Ana Maria Almeida. (Orgs). Teoria e prática na pesquisa com crianças: diálogos com William Corsaro. São Paulo: Cortez, 2009b.

CORSARO, Willian A. Sociologia da infância. Tradução de Lia Gabriele Regius Reis. Porto Alegre: Artmed, 2011.

CRUZ, Silvia Helena Vieira. (Org.). A criança fala: a escuta de crianças em pesquisas. São Paulo: Cortez, 2008.

DELGADO, Ana Cristina Coll; MÜLLER, Fernanda. Abordagens etnográficas nas pesquisas com crianças. In: CRUZ, Silvia Helena Vieira (Org.). A criança fala: a escuta de crianças em pesquisas. São Paulo: Cortez, 2008.

FARIA, Ana Lúcia Goulart de. Pequena infância, educação e gênero: subsídios para um estado da arte. Cadernos Pagu, n. 26, p 279-287, jan-jun. 2006. Disponível em: http//www.scielo.br/pdf/cpa/n26/30394.pdf. Acesso em 20. Dez. 2012. 
Ericka Marcelle Barbosa de Oliveira

Lenira Haddad

FELIPE, Jane; GUIZZO, Bianca Salazar. Entre batons, esmaltes e fantasias. In: MEYER, Dagmar Estermann; SOARES, Rosângela de Fátima Rodrigues (Orgs.). Corpo, gênero e sexualidade. 2. ed. Porto Alegre: Mediação, 2008. FERREIRA, Maria Manuela Martinho. “- A gente aqui o que gosta mais é de brincar com os outros meninos!" - as crianças como atores sociais e a (re) organização social do grupo de pares no cotidiano de um Jardim de Infância. Dissertação de doutoramento em Ciências da Educação, Universidade do Porto, Faculdade de Psicologia e Ciências da Educação, 2002.

FINCO, Daniela. Educação infantil, espaços de confronto e convívio com as diferenças: análise das interações entre professoras e meninos e meninas que transgridem as fronteiras de gênero. Tese de Doutorado (Doutorado em Sociologia da Educação). Universidade de São Paulo, 2010.

GRAUE, M. Elizabeth; WALSH, Daniel. Investigação etnográfica com crianças: teorias, métodos e ética. Lisboa: Fundação Calouste Gulbenkian, 2003.

GROSSI, Mirian Pilar. Identidade de gênero e sexualidade. Florianópolis: UFSC, $1998 . \quad$ Disponível em $<$ http://miriamgrossi.paginas.ufsc.br/files/2012/03/grossi_miriam_identidad $\mathrm{e}_{-}$

de_genero_e_sexualidade.pdf >. Acesso em 12. Dez. 2014.

LOURO, Guacira Lopes. Gênero, sexualidade e educação: uma perspectiva pós-estruturalista. 12ed. Petrópolis, RJ: Vozes, 2011.

LOURO, Guacira Lopes. Uma sequência de atos. Cult, São Paulo, v.185, Nov 2013. Disponível em: http://revistacult.uol.com.br/home/2013/11/umasequencia-de-atos/ Acesso 20. Jan. 2015.

MEYER, Dagmar Estermann. Gênero e educação: teoria e política. In: LOURO, Guacira Lopes; FELIPE, Jane; GOELLNER, Silvana Vilodre. (Orgs.). Corpo, gênero e sexualidade: um debate contemporâneo na educação. 3. ed. Petrópolis, RJ: Vozes, 2007.

MEYER, Dagmar Estermann; SOARES, Rosângela de Fátima Rodrigues. Corpo, gênero e sexualidade nas práticas escolares: um início de reflexão In: MEYER, Dagmar Estermann; SOARES, Rosângela de Fátima Rodrigues (Orgs.). Corpo, gênero, e sexualidade. 2. ed. Porto Alegre: Mediação, 2008. ROCHA, Eloísa Acires Candal. Por que ouvir as crianças? Algumas questões para um debate científico multidisciplinar. In: CRUZ, Silvia 
Entre Meninos e Meninas: Fronteiras de Gênero Borradas em Contexto de Educação Infantil

Helena Vieira (Org.) A criança fala: a escuta de crianças em pesquisas. São Paulo: Cortez, 2008.

ROSEMBERG, Fúlvia. Caminhos cruzados: educação e gênero na produção acadêmica. Educação e Pesquisa. São Paulo, v. 27, n. 1, p. 47-68, 2001.

SCOTT, Joan Wallach. Gênero: uma categoria útil de análise histórica. Tradução de Christine Rufino Dabat e Maria Betânia Ávila. Recife: SOS Corpo, $1991 . \quad$ Disponível em $<$ http://disciplinas.stoa.usp.br/pluginfile.php/185058/mod_resource/content /2/G\%C3\%AAnero-Joan\%20Scott.pdf> Acesso em 12. Dez. 2014.

THORNE, Barrie. Gender Play: girls and boys in school. Open University Press Buckingham, 1993.

WEST, Candace; ZIMMERMAN, Don H. Doing Gender. Gender and Society, Vol. 1, No. 2, 125-151. 1987. Tradução livre de Márcia Buss-Simão. 